\title{
Hypothermic stress leads to activation of Ras-Erk signaling
}

\author{
Edmond Y.W. Chan, Stacey L. Stang, Drell A. Bottorff, and James C. Stone \\ Department of Biochemistry, University of Alberta, Edmonton, Alberta, Canada, T6G 2H7 \\ Address correspondence to: James C. Stone, Department of Biochemistry, University of Alberta, Edmonton, Alberta, Canada, T6G \\ 2H7. Phone: (708) 492-7976; Fax: (708) 492-9556; E-mail: jim.stone@ualberta.ca
}

Received for publication October 12, 1998, and accepted in revised form March 30, 1999.

\begin{abstract}
The small GTPase Ras is converted to the active, GTP-bound state during exposure of vertebrate cells to hypothermic stress. This activation occurs more rapidly than can be accounted for by spontaneous nucleotide exchange. Ras-guanyl nucleotide exchange factors and Ras GTPase-activating proteins have significant activity at $0^{\circ} \mathrm{C}$ in vitro, leading to the hypothesis that normal Ras regulators influence the relative amounts of Ras-GTP and Ras-GDP at low temperatures in vivo. When hypothermic cells are warmed to $37^{\circ} \mathrm{C}$, the Raf-Mek-Erk protein kinase cascade is activated. After prolonged hypothermic stress, followed by warming to physiologic temperature, cultured fibroblasts assume a rounded morphology, detach from the substratum, and die. All of these biologic responses are attenuated by pharmacologic inhibition of Mek. Previously, it had been found that low temperature blocks acute growth factor signaling to Erk. In the present study, we found that this block occurs at the level of Raf activation. Temperature regulation of Ras signaling could help animal cells respond appropriately to hypothermic stress, and Ras-Erk signaling can be manipulated to improve the survival of cells in cold storage.
\end{abstract}

J. Clin. Invest. 103:1337-1344 (1999).

\section{Introduction}

The low-molecular-weight GTPase Ras exists on the inner surface of the plasma membrane, where it functions as a molecular switch that links extracellular signals to intracellular biochemical responses (1). The role of Ras in peptide growth factor signaling is particularly well understood. When cells are treated with EGF, for example, the extracellular domain of the EGF receptor binds EGF, and the intracellular protein tyrosine kinase domain undergoes autophosphorylation (2). Proteins such as Grb2 and Shc then serve as adapters that form a bridge between the receptor and Sos, a Ras-guanyl nucleotide exchange factor (Ras-GEF) $(3,4)$. The net effect is to recruit Sos to the membrane, where it can activate Ras. Active Ras-GTP then signals to various effector systems such as the RafMek-Erk protein kinase cascade (5). This signaling is normally attenuated by GTPase-activating proteins (GAPs) that stimulate conversion of Ras to the inactive, GDPbound state (6). Ras signaling has been implicated in a number of biologic processes including cell division (7), cell adhesion $(8,9)$, cytoskeletal rearrangements $(10)$, differentiation (5), and cell survival $(11,12)$.

Here we show that hypothermic stress leads to activation of Ras in rat fibroblasts. Furthermore, the Raf-MekErk kinase cascade is rapidly activated when hypothermic cells are returned to physiologic temperature. Previously, it had been found that low temperatures block acute growth factor signaling $(13,14)$. When fibroblasts are exposed to EGF at $4^{\circ} \mathrm{C}$, Erk is not activated (14). This temperature effect is not due to trivial effects on ATP levels, for example, as autophosphorylation of the receptor at low temperature is readily detectable.

Hypothermia is a common environmental stress sustained by many species. Furthermore, hypothermia is often used to preserve human cells, tissues, and organs for transplantation. In this latter situation, hypothermia is thought to protect cells by slowing metabolism during the anoxic storage period. Hypothermic stress can also cause cell damage, however. This damage could stem from decreased ATP synthesis, failure to maintain cellular membrane $\mathrm{Na}^{+}$and $\mathrm{Ca}^{2+}$ ion gradients, cell swelling, and activation of phospholipases (15-18). Hypothermia is also a recognized trigger of apoptosis (programmed cell death) (19-21). Little is known about specific biochemical pathways that are activated in response to hypothermic stress, however. Furthermore, the relationship between known biochemical changes in hypothermic cells and cell damage is not understood.

We studied the mechanism and consequences of Ras activation in cultured cells exposed to hypothermia. We also determined the level in the signaling cascade at which low temperature blocks acute EGF signaling in fibroblasts.

\section{Methods}

Cell culture. Rat2 cells have been described previously $(22,23)$. $\mathrm{H}$-Ras and Raf1 were overexpressed using the retrovirus vector $\mathrm{pBabePuro}$ and a helper-free retrovirus packaging system (24, 25). Madin-Darby canine kidney (MDCK) and primary human lip fibroblasts (KD) cells were kindly provided by M. Pasdar and R. Day (both of the University of Alberta), respectively. Primary chicken embryonic fibroblasts (CEFs) were purchased from Spafas Inc.,(Preston, Connecticut, USA) and primary rat embryo cells (RECs) were purchased from BioWhittaker Inc. (Walkersville, Maryland, USA). Normal growth medium for all cells was DMEM $/ 10 \%$ FBS, except for CEFs, which were maintained in DMEM/10\% tryptose phosphate broth $/ 1.1 \%$ chicken serum $/ 4.4 \%$ calf serum. When indicated, cells were given a pretreatment of $50 \mu \mathrm{M}$ PD098059 (Calbiochem-Novabiochem Corp., La Jolla, California, USA) or DMSO (0.1\%) vehicle control for 90 minutes before cooling.

For studies involving activation of Ras, cells were incubated on ice in either DMEM/0.5\% dialyzed FBS (Figure 1a) or DMEM/10\% FBS (Figure 1b). To study biochemical events dur- 
a

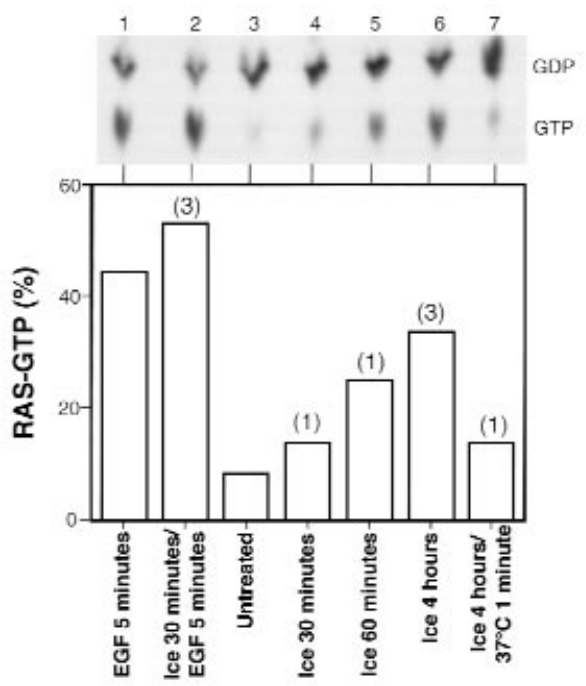

b

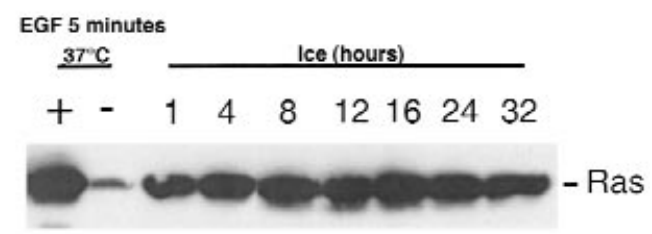

Figure 1

Activation of Ras in response to hypothermic stress. (a) Ras-GTP was measured in rat 2 cells using a ${ }^{32} \mathrm{P}_{\mathrm{i}}$ labeling method. As a control, cells were stimulated with $\operatorname{EGF}(100 \mathrm{ng} / \mathrm{mL})$ at $37^{\circ} \mathrm{C}$ (lane 1$)$. In lanes 4-6, cells were incubated on ice for the indicated times. In lane 7 , cells were incubated on ice for 4 hours and then warmed to $37^{\circ} \mathrm{C}$ for 1 minute. After cell lysis and immunoprecipitation of Ras, the levels of associated GTP and GDP were determined. Top: Autoradiogram showing radiolabeled GDP and GTP after separation by chromatography. Bottom: The results at the top have been plotted as percent GTP relative to GTP + GDP. The results shown in lanes 1 and 3 have been observed numerous times. Numbers of independent times such observations were made are shown above other bars. Note that the data in lane 2 (cells were incubated on ice for $30 \mathrm{~min}$ utes and then stimulated with EGF for 5 minutes on ice) concern the lowtemperature block to acute EGF signaling. (b) Rat2 cells overexpressing wild-type $\mathrm{H}$-Ras were incubated on ice for 1-32 hours. Ras-GTP was precipitated from cell lysates with a GST-Raf fusion protein, and precipitated Ras was detected with an anti-Ras immunoblot method.

ing the warming period, cells were incubated on ice in normal growth medium for the indicated amounts of time and then warmed using one of two protocols. To study early events after recovery from hypothermic conditions, the temperature was raised quickly with an "add back" protocol. In this method, growth medium was removed from the culture during the last 15 minutes of incubation at $0^{\circ} \mathrm{C}$. This medium was warmed to $37^{\circ} \mathrm{C}$ and then added back to the original culture at the start of the recovery period, as the culture was placed in a $37^{\circ} \mathrm{C}$ water bath. In the second "shift" protocol, cultures were simply transferred from ice to a warm metal tray in a $37^{\circ} \mathrm{C} \mathrm{CO}_{2}$ incubator. This treatment was used in two experiments (see Figure 5 a and d). Using this second protocol, the temperature takes several minutes to rise. Thus, the kinetics of reactions are not directly comparable between different figures.

Biochemistry. To measure Ras activation, rat 2 cells were labeled with ${ }^{32} \mathrm{P}_{\mathrm{i}}$ for 4 hours. After various treatments, cells were lysed and Ras was immunoprecipitated with antibody Y13-259. Rasassociated guanyl nucleotides were then separated by chromatography on cellulose-polyethyleneimine (PEI) and analyzed by PhosphorImager (MacBas 1000, Fuji Film Corp., Stamford, Connecticut, USA) analysis (23). Alternatively, Ras activation was assayed by a nonisotopic method that takes advantage of the ability of Ras-GTP to bind to the Ras-binding domain of Raf (26). Rat2 cells overexpressing wild-type H-Ras were lysed after various periods of incubation at $0^{\circ} \mathrm{C}$. Lysates were incubated for 30 minutes at $4^{\circ} \mathrm{C}$ with $30-50 \mu \mathrm{g}$ GST-RBD (GST fused to amino acid 1-149 of wild-type Raf-1) bound to glutathioneSepharose. Precipitated Ras was resolved on 11\% SDS-PAGE and detected by immunoblotting with an anti-Ras mAb (R02120; Transduction Laboratories, Lexington, Kentucky, USA).

H-Ras was expressed in Escherichia coli and purified by chromatography. Because some exchange factors may work better with substrate Ras that has been fully processed, we also used $6 \times$ His-tagged Ras that was expressed in Sf9 cells using a baculovirus expression system and purified by nickel chromatography. To assess spontaneous association of guanyl nucleotide in vitro, bacterial Ras-GDP complex was incubated with a molar excess of $\left[\alpha^{-32} \mathrm{P}\right] \mathrm{GTP}$ in a $0.2-\mathrm{mL}$ reaction, either on ice or at $30^{\circ} \mathrm{C}$. Reactions contained $50 \mathrm{mM}$ Tris (pH 8.0), $5 \mathrm{mM}$ $\mathrm{MgCl}_{2}, 5 \mathrm{mM} \mathrm{NaCl}, 1 \mathrm{mM}$ DTT, $0.2 \mathrm{mg} / \mathrm{mL}$ BSA, $1 \mu \mathrm{M}$ RasGDP, and $100 \mu \mathrm{M}$ GTP including $40 \mu \mathrm{Ci}\left[\alpha_{-}{ }^{32} \mathrm{P}\right] \mathrm{GTP}$. At various times, $0.05-\mathrm{mL}$ aliquots were removed and Ras was immunoprecipitated with antibody Y13-259. Precipitated guanyl nucleotides were dissociated, chromatographed on cellulose-PEI, and quantified by PhosphorImager analysis. Maximal Ras loading was determined by adding EDTA followed by titration with excess $\mathrm{MgCl}_{2}$. We also studied association using processed Ras and recombinant Ras-GEFs. These reactions $(0.05 \mathrm{~mL})$ contained $20 \mathrm{mM}$ Tris ( $\mathrm{pH} 7.5), 5 \mathrm{mM} \mathrm{MgCl}_{2}, 100$ $\mathrm{mM} \mathrm{NaCl}, 1 \mathrm{mM} \mathrm{DTT}, 10 \% \mathrm{vol} / \mathrm{vol}$ glycerol, $0.2 \mathrm{mg} / \mathrm{mL}$ BSA, $0.2 \mu \mathrm{M}$ Ras-GDP, and $1 \mu \mathrm{M}$ GTP including $10 \mu \mathrm{Ci}\left[\alpha_{-}{ }^{32} \mathrm{P}\right] \mathrm{GTP}$. Reactions also included $0.1 \mu \mathrm{g}$ purified $6 \times$ His-tagged p30GRF1, the catalytic domain of Ras-GRF1 (27).

To assess guanyl nucleotide hydrolysis, $6 \times$ His-Ras was bound to $\left[\alpha-{ }^{32} \mathrm{P}\right] \mathrm{GTP}$ and separated from free nucleotide on PD10 desalting columns (Amersham Pharmacia Biotech, Inc., Baied'Urfé, Québec, Canada). Reactions $(0.06 \mathrm{~mL})$ contained 20 $\mathrm{mM}$ HEPES (pH 7.2), $2 \mathrm{mM} \mathrm{MgCl} 2,5 \mathrm{mM}$ DTT, $0.5 \mathrm{mg} / \mathrm{mL}$ BSA, and approximately $0.04 \mu \mathrm{g}$ Ras- $\left[\alpha-{ }^{32} \mathrm{P}\right] \mathrm{GTP}$ complex. When indicated, reactions also contained $0.3 \mu \mathrm{g}$ purified p120GAP. After incubations, Ras-associated guanyl nucleotides were precipitated and analyzed as described earlier here.

To measure Raf- 1 activity, rat 2 cells overexpressing wild-type Raf-1 were lysed in buffer containing $20 \mathrm{mM}$ Tris ( $\mathrm{pH}$ 8.0), 137 $\mathrm{mM} \mathrm{NaCl}, 2 \mathrm{mM}$ EDTA, 10\% vol/vol glycerol, $1 \% \mathrm{vol} / \mathrm{vol} \mathrm{NP} 40$, $0.1 \% \mathrm{wt} / \mathrm{vol}$ SDS, $0.5 \% \mathrm{wt} / \mathrm{vol}$ sodium deoxycholate (DOC), 2 $\mu \mathrm{g} / \mathrm{mL}$ leupeptin (Boehringer Mannheim, Laval, Québec, Canada), $20 \mu \mathrm{g} / \mathrm{mL}$ aprotinin (Sigma Chemical Co., St. Louis, Missouri, USA), and $1 \mathrm{mM}$ Pefa (Boehringer Mannheim). After the lysates were cleared by centrifugation, Raf- 1 was immunoprecipitated with the anti-Raf-1 polyclonal antibody (C-12; Santa Cruz Biotechnology Inc., Santa Cruz, California, USA) bound to protein A-Sepharose. Immunoprecipitates were washed with DOC- and SDS-free lysis buffer and incubated in a final volume of $0.06 \mathrm{~mL}$ at $30^{\circ} \mathrm{C}$ with $0.5 \mu \mathrm{g}$ GST-MEK fusion protein, $2 \mu \mathrm{g}$ recombinant kinase-defective Erk in $30 \mathrm{mM}$ HEPES ( $\mathrm{pH}$ 7.4), $10 \mathrm{mM} \mathrm{MgCl}_{2}, 7 \mathrm{mM} \mathrm{MnCl}_{2}, 2 \mathrm{mM}$ DTT, and $20 \mu \mathrm{M}$ ATP containing $10 \mu \mathrm{Ci}\left[\gamma^{-32} \mathrm{P}\right] \mathrm{ATP}$. After 30 minutes, the reaction was stopped with SDS sample buffer and the products were resolved by SDS/PAGE. Proteins were transferred to nitrocellulose, and radiolabeled Erk was quantified by PhosphorImager analysis. Similarly, Mek1 was precipitated with an mAb (M17020; Transduction Laboratories), and activity was assayed using kinase-defective Erk as substrate (28).

Erk activation was measured in a mobility shift assay by resolving proteins on SDS-PAGE and immunoblotting with anti-MAPK mAb (13-6200; Zymed Inc., Camarillo, California, 
USA). Alternatively, proteins resolved by SDS-PAGE were immunoblotted with an antibody directed against phosphorylated Erk (9105; New England Biolabs Inc., Beverly, Massachusetts, USA). To demonstrate equivalent amounts of Erk in each lysate, a parallel immunoblot was performed with anti-Erk polyclonal antibody (sc-94; Santa Cruz Biotechnology Inc.). To assess tyrosine phosphorylation of Erk and Shc, cell lysates were resolved by SDS-PAGE and immunoblotted with a cocktail of 2 different anti-phosphotyrosine mAb's (4G10 from Upstate Biotechnology Inc., Lake Placid, New York, USA; PY69 from Santa Cruz Biotechnology Inc.). The identities of Erk and Shc were confirmed by immunoblotting these lysates with antibodies that recognize these 2 proteins.

Viability studies. To assay cell viability after prolonged hypothermia, rat2 cells, RECs, and MDCK cells were pretreated with PD098059 $(50 \mu \mathrm{M})$ or DMSO vehicle control and then incubated in an ice-water bath for 0-72 hours in a tightly sealed tissue culture flask containing a $10 \% \mathrm{CO}_{2}$ environment. Cells were then warmed to $37^{\circ} \mathrm{C}$ for 4 hours. Both substrate-attached and-detached cells were pooled and plated at low density to determine the number of viable colony-forming units. The remainder of each sample was incubated for 4 hours at $37^{\circ} \mathrm{C}$ in a $25-\mathrm{cm}^{2}$ tissue culture flask to allow reattachment. Reattached (i.e., viable) cells were then trypsinized and counted with a Coulter counter (Coulter Electronics Ltd., Hialeah, Florida, USA). Counting colonies from the low-density cultures after 12 days' incubation provided an alternative index of cell survival, with similar results.

\section{Results}

Ras is activated in response to bypothermic stress. Ras activation in rat2 fibroblasts was assessed by measuring the ${ }^{32} \mathrm{P}$ labeled guanyl nucleotides associated with Ras (Figure 1a) and by measuring the amount of Ras-GTP that could be precipitated from lysates using a GST-Raf fusion protein (Figure 1b). Ras is primarily GDP bound in untreated cells. We discovered that Ras-GTP slowly accumulates in cells exposed to $0^{\circ} \mathrm{C}$ in normal growth medium. Within 4 hours of $0^{\circ} \mathrm{C}$ incubation, the amount of Ras-GTP (33\%) approaches levels obtained after acute EGF stimulation at $37^{\circ} \mathrm{C}(44 \%)$. Remarkably, this activated state can persist for at least 32 hours. After rewarming, Ras-GTP levels decrease within 1 minute (Figure 1a). The results shown in Figure 1a obtained with cells treated at $0^{\circ} \mathrm{C}$ with EGF are discussed later here.

Ras-GTP association and bydrolysis at $0^{\circ} \mathrm{C}$. To understand how Ras might be activated in hypothermic cells, we studied spontaneous and catalyzed GTP hydrolysis and guanyl nucleotide exchange reactions in vitro, using recombinant proteins. Because in vivo Ras activation at $0^{\circ} \mathrm{C}$ was slow and increased over a 4-hour period, we studied the extent of these reactions over this period. Recombinant Ras copurifies with GDP (29). After incubating Ras-GDP with an excess of labeled GTP for 4 hours at $30^{\circ} \mathrm{C}, 53 \%$ of Ras was associated with labeled guanyl nucleotide and $75 \%$ of this was hydrolyzed to GDP. By contrast, after incubation at $0^{\circ} \mathrm{C}$, we observed that only $3 \%$ of Ras was associated with exogenous nucleotide (Figure 2a). In this case, about $15 \%$ was hydrolyzed to GDP, and the remaining $85 \%$ was present as GTP. Thus, spontaneous dissociation of Ras-GDP and association of GTP with Ras are very slow at $0^{\circ} \mathrm{C}$.

p120GAP is a major Ras-GAP in fibroblasts, and we found that this enzyme retained considerable activity at a

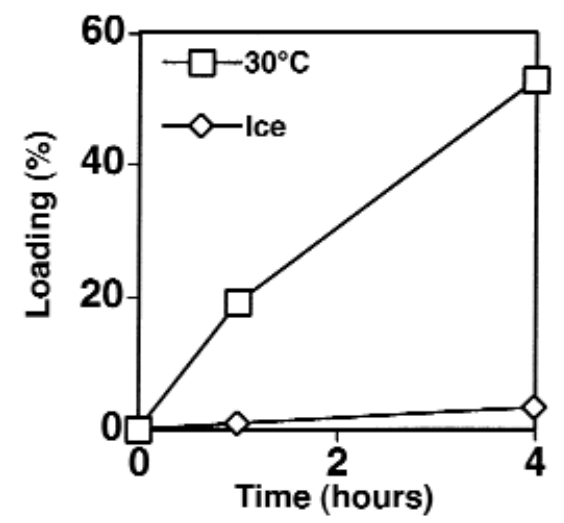

b

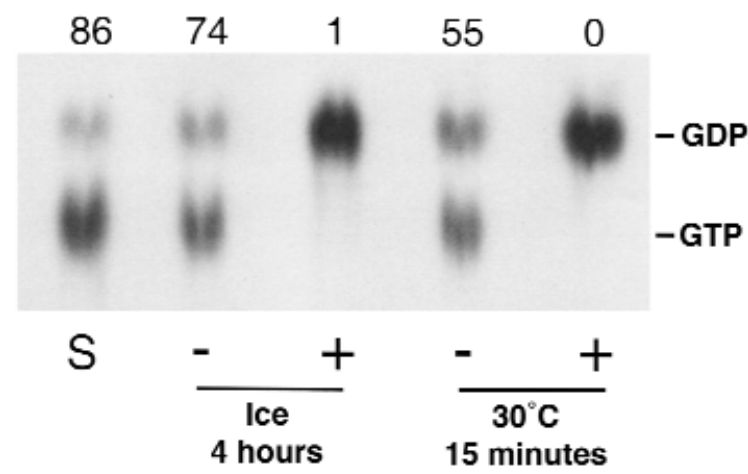

C

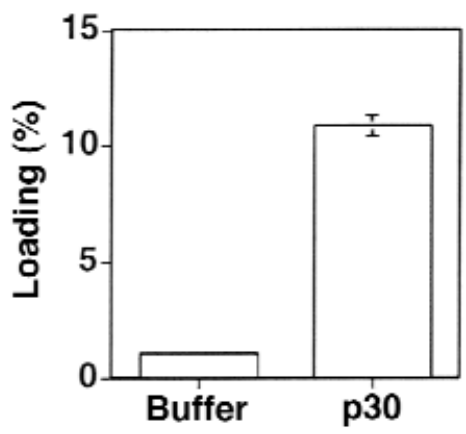

Figure 2

In vitro Ras-GTP association and hydrolysis at $0^{\circ} \mathrm{C}$. (a) Ras-GDP complex from $E$. coli was incubated with a molar excess of $[\alpha-32 \mathrm{P}] \mathrm{GTP}$ at $30^{\circ} \mathrm{C}$ or at $0^{\circ} \mathrm{C}$ for up to 4 hours followed by precipitation and quantification of Ras-associated label. Values are expressed as percent of maximal association, as determined by equilibration in magnesium-free conditions. Values shown are averages of duplicate data points. (b) Ras from Sf9 cells was complexed with $\left[\alpha_{-}{ }^{32} \mathrm{P}\right]$ GTP and then incubated either with $(+)$ or without (-) recombinant $\mathrm{P} 120 \mathrm{GAP}$ at $0^{\circ} \mathrm{C}$ for 4 hours or at $30^{\circ} \mathrm{C}$ for 15 minutes. Ras-associated nucleotide was then precipitated and quantified. Lane $S$ represents the starting material, substrate Ras-GTP complex that was precipitated immediately. The percent of total radiolabel that was present as GTP is shown above each lane. Chromatographic positions of GDP and GTP are shown on the right. (c) Ras-GDP from Sf9 cells was incubated at $0^{\circ} \mathrm{C}$ with a molar excess of $\left[\alpha_{-}^{32} \mathrm{P}\right]$ GTP in the presence (p30) or absence (buffer) of the catalytic domain of Ras-GRF1 for 4 hours. Newly associated radiolabeled nucleotide was precipitated and quantified. Values are expressed as percent of maximal association and are the averages of triplicate data points with the standard deviation indicated. Note that when parallel reactions were performed at $30^{\circ} \mathrm{C}$ for 15 minutes, spontaneous and catalyzed association values of $4 \%$ and $43 \%$, respectively, were observed 


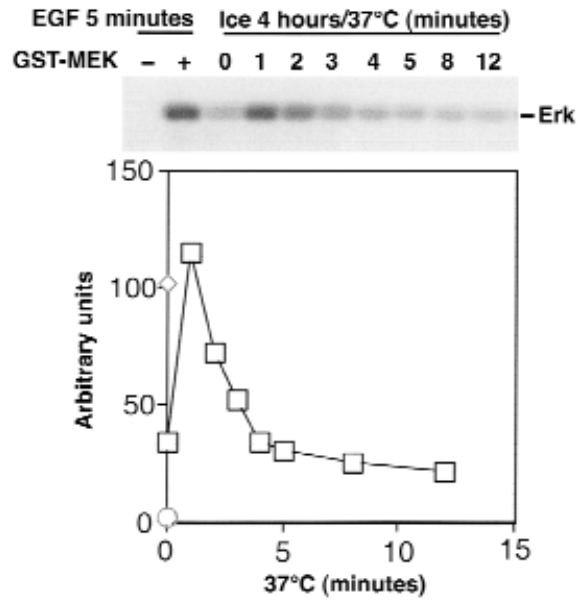

b

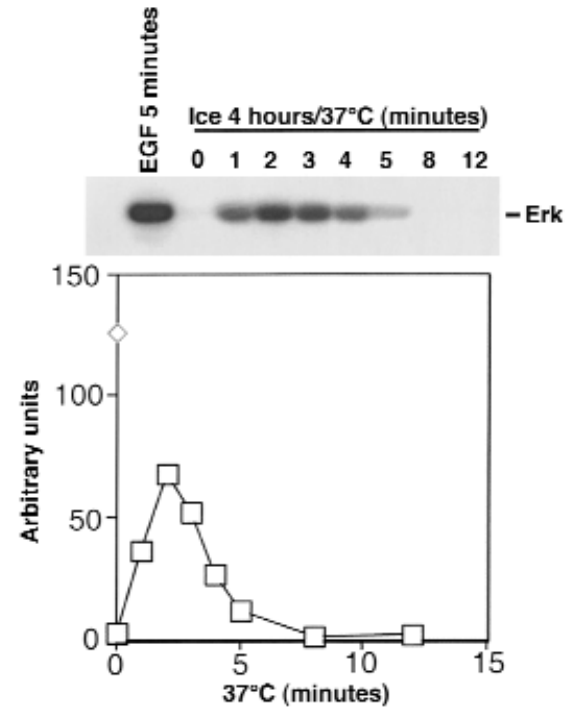

c

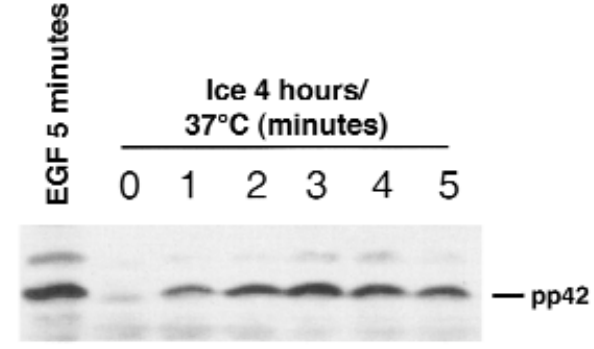

Figure 3

Activation of the Raf-Mek-Erk protein kinase cascade during recovery from hypothermia. (a-c). Rat 2 cells overexpressing wild-type Raf- 1 were incubated on ice for 4 hours and then warmed to $37^{\circ} \mathrm{C}$ for $1-12$ minutes. Samples of each lysate were assayed for Raf-1 or Mek-1 activity using immune-complex kinase assays, or for tyrosine phosphorylation of Erk using an immunoblot method. (a) In this assay, Raf activates GST-MEK1 to incorporate radioactivity onto a kinase-defective Erk substrate. As controls, EGF-treated cells were assayed for Raf-1 activity either without or with GST-MEK1 as substrate. Top: Autoradiogram. Bottom: Raf activity is plotted quantitatively. Circle represents EGF treatment without GSTMEK1. Diamond represents EGF-treated positive control. Squares represent time course of Raf-1 activation. (b) Mek-1 activity was determined by immunoprecipitation with an anti-Mek-1 antibody. Top: Autoradiogram. Bottom: Mek activity is plotted quantitatively. Diamond represents EGF-treated positive control. Squares represent time course of Mek1 activation. (c) The levels of Erk tyrosine phosphorylation were determined by immunoblotting with anti-phosphotyrosine antibodies. The position of pp42 Erk is shown on the right. $0^{\circ} \mathrm{C}$ when assayed over a 4-hour period (Figure $2 \mathrm{~b}$ ). Similar results were obtained with the catalytic domain of neurofibromin, another Ras-GAP (data not shown). We also examined the ability of 2 Ras-GEFs to function at $0^{\circ} \mathrm{C}$. The catalytic domain of GRF1 caused a 10 -fold increase in the formation of Ras-GTP relative to the noncatalyzed GTP association reaction (Figure 2c). Ras-GRP, another Ras activator in the CDC25 family (30), similarly displayed considerable activity (data not shown).

The Raf-Mek-Erk kinase cascade is activated during recovery from bypothermia. To address the biochemical consequences of Ras activation by hypothermic stress, we examined the status of the Raf-Mek-Erk protein kinase cascade at various times after recovery from 4 hours of hypothermic stress. Using an immune-complex kinase assay, Raf1 was found to be maximally activated 1 minute after rewarming to $37^{\circ} \mathrm{C}$ (Figure 3a), whereas Mek1 was maximally activated after 2 minutes (Figure $3 \mathrm{~b}$ ). Tyrosine phosphorylation of Erk, a marker for activation by Mek, was maximal at 3 minutes (Figure 3c). A protein kinase downstream of Erk, p90 ${ }^{\text {rsk }}$, was also activated after recovery from cold (data not shown). No activation of the kinase cascade was evident without rewarming. Thus, Ras activation by hypothermic stress leads to a typical biochemical effector response during the recovery period. The stress kinases SapK and p38HOG were only slightly activated during recovery from hypothermic stress, consistent with our observation that these kinases are not regulated by Ras in rat 2 cells (data not shown).

Inhibition of EGF signaling at low temperature involves a failure to activate Raf1 but not Ras. In parallel with the experiments just described, we addressed the mechanism underlying the previously documented effect of low temperature on EGF signaling (14). When we exposed rat2 cells to EGF at $0^{\circ} \mathrm{C}$, Ras-GTP increased rapidly (Figure 1a, lane 2). Thus, low temperature does not inhibit EGF activation of Ras. Using an anti-phosphotyrosine blotting method, we confirmed that EGF treatment at $37^{\circ} \mathrm{C}$ resulted in prompt tyrosine phosphorylation of both She and Erk (Figure 4a). In agreement with previous work, we found that low temperature blocks EGF signaling to Erk. However, we found that low temperature did not inhibit EGF-induced tyrosine phosphorylation of Shc, as expected from our results with EGF activation of Ras at $0^{\circ} \mathrm{C}$.

Using an immune-complex kinase assay we found that Raf was only marginally activated when cells were treated with EGF at $0^{\circ} \mathrm{C}$ (Figure 4b). Therefore, acute EGF signaling at $0^{\circ} \mathrm{C}$ is efficient to the point at which Ras is activated, but Raf activation is largely blocked.

Activation of Erk signaling after recovery from bypothermic stress is widespread in vertebrate cells. We used Erk phosphorylation assays to explore the circumstances in which Ras-Erk signaling is subjected to temperature regulation. In rat 2 cells, the degree of Erk activation is proportional to the duration of hypothermia up to 4 hours, at which point Erk is fully activated (Figure 5a). As expected, Erk activation after hypothermic stress was blocked by PD098059, a specific inhibitor of Mek activation (31). Cells were exposed to various temperatures for a 4-hour period and then examined for Erk activation after briefly incubating at $37^{\circ} \mathrm{C}$. We found that $4^{\circ} \mathrm{C}$ was sufficient to elicit robust Erk activation and that $10^{\circ} \mathrm{C}$ led to signifi- 


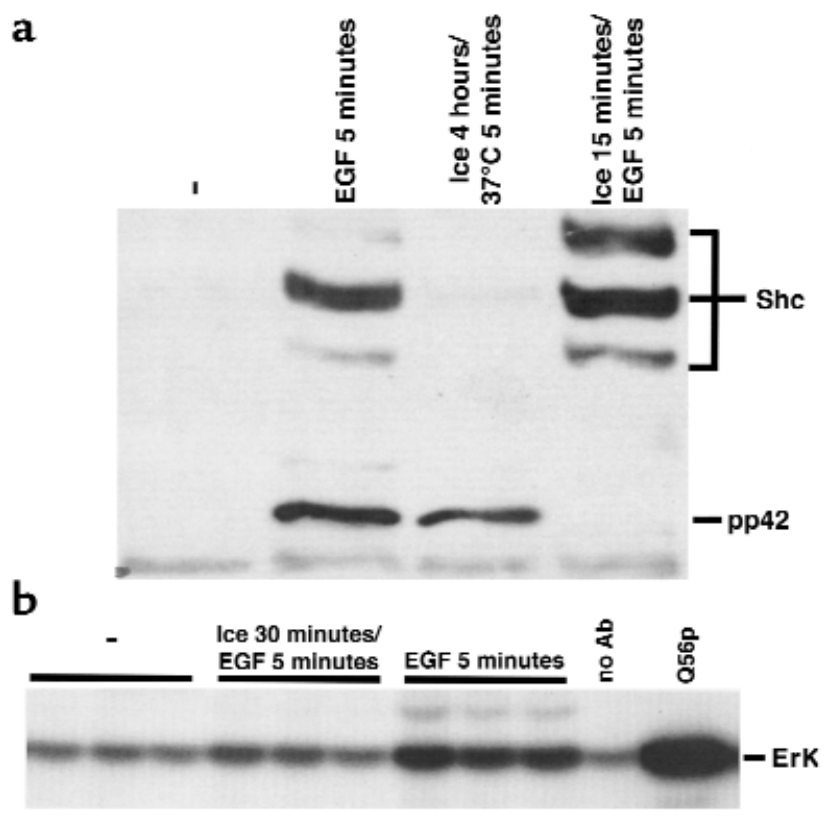

Figure 4

Low temperature blocks acute growth factor activation of Raf and Erk but not Shc. (a) Rat2 cells were left untreated, stimulated with EGF at $37^{\circ} \mathrm{C}$, incubated on ice for 4 hours followed by warming to $37^{\circ} \mathrm{C}$ for 5 minutes, or chilled on ice for 15 minutes followed by EGF stimulation on ice. Cellular proteins were then analyzed using a phosphotyrosine immunoblot method. The positions of pp42 Erk and the different tyrosine-phosphorylated Shc species are shown on the right. (b) Rat2 cells overexpressing wild-type Raf- 1 were left untreated, chilled on ice for 30 minutes, and then stimulated with EGF on ice, or stimulated with EGF at $37^{\circ} \mathrm{C}$. Raf was immunoprecipitated and assayed for catalytic activity (at $30^{\circ} \mathrm{C}$ ), as described in Figure 3a. Triplicate samples shown are from 3 independent plates of cells. As negative and positive controls, respectively, no antibody was used to immunoprecipitate Raf from EGF-treated cells, and recombinant GST-Mek1 (Q56P) (mutationally activated) was used in place of Raf1 and wild-type GST-Mek1.

cant Erk activation in the period after stress (Figure 5b). Our observations do not reflect an idiosyncrasy of rat2 fibroblasts. MDCK cells, KD cells (primary human fibroblasts), CEFs, and RECs all showed activation of Erk during recovery from hypothermic stress (Figure 5c).

We also found that the previously documented inhibition of acute growth factor signaling at $0^{\circ} \mathrm{C}$ was a feature of each of the cultured cell types.

Pharmacologic inbibition of Mek promotes cell viability after prolonged hypothermic stress. We studied cultured cells exposed to prolonged hypothermia to determine whether Ras signaling influences viability. We first determined hypothermic exposure times that resulted in a substantial loss of viability for various cells types. We then confirmed that Erk can be activated after recovery from prolonged hypothermia and that this biochemical response is blocked by PD098059 pretreatment (Figure 5d).

During the period of prolonged $0^{\circ} \mathrm{C}$ incubation, rat 2 cells and RECs remain attached and have a near-normal morphology. Immediately after warming, the cells start to become rounded, and after 4 hours, many are detached from the substratum (Figure 6a). When both the detached and attached cells are pooled and replated, a substantial loss of viability is evident from the failure of cells to reattach and to form colonies (Figure 6b). Similar results were obtained with the MDCK epithelial cell line (Figure $6 \mathrm{c}$ ) and KD human fibroblasts. Treatment with the Mek inhibitor PD098059 prevented the change in REC and rat2 cell morphology and substantially increased viability in all cells tested. The Mek inhibitor U0126 (32) similarly protected rat2 cells from the detrimental effects of prolonged hypothermic stress.

\section{Discussion}

Ras is activated in response to hypothermic stress in rat2 fibroblasts, as assessed by 2 different methods. The activation of Ras occurs over a period of several hours, persists for many hours, and is comparable in magnitude to that achieved by acute growth factor signaling. From our analysis of phosphotyrosine-containing proteins, we have concluded that the activation of Ras in response to hypothermic stress occurs without overt activation of upstream growth factor signaling components such as She (Figure 4a, lane 3). However, Ras activation is slow in the cold, and the lack of overt activation does not rule out a role for conventional components of the Ras-activation mechanism.

Very little Ras-GTP was formed when purified RasGDP complex was incubated in vitro with an excess of labeled GTP for 4 hours at $0^{\circ} \mathrm{C}$. Furthermore, 2 wellcharacterized Ras-GAPs did demonstrate activity at $0^{\circ} \mathrm{C}$. We also found that Ras-GEFs of the CDC25 family had substantial activity in vitro at $0^{\circ} \mathrm{C}$. Our studies do not provide a quantitative account of how temperature would affect the equilibrium between Ras-GDP and Ras-GTP in vivo. The amounts of Ras-GAPs and RasGEFs used in our in vitro experiments were arbitrary and likely do not reflect the relative activities of these factors in cells. However, we have shown that it is difficult to account for Ras activation in vivo without invoking Ras-GEF activity, and we have shown that Ras-GEFs can work at low temperature. These observations lead us to propose that Ras-GEFs do contribute to Ras activation in hypothermic cells. Our observations on the effects of cold on EGF signaling are also germane to this argument (see later discussion).

Upon rewarming to $37^{\circ} \mathrm{C}$, cellular Ras-GTP promptly decreases. However, a brief but typical Ras effector response occurs upon warming, as evident from the sequential and robust activation of Raf, Mek, and Erk. We observed only a modest activation of the conventional stress kinases JNK/SapK and p38HOG. Furthermore, these pathways do not appear to be directly regulated by Ras in rat 2 fibroblasts. Although many other biochemical changes no doubt occur, hypothermic stress followed by warming appears to activate Ras-Erk signaling specifically and strongly.

We also show here that the previously described inhibition of EGF signaling to Erk at low temperature involves a block in Raf activation. Importantly, EGF signaling to the level of Ras activation is efficient at $0^{\circ} \mathrm{C}$. Indeed, slightly more Ras-GTP was formed within 5 minutes of EGF treatment at $0^{\circ} \mathrm{C}$ than was formed with EGF treatment at $37^{\circ} \mathrm{C}$. EGF signaling to Ras in fibroblasts at normal temperatures almost certainly involves activation of Ras GEFs such as Sos (3). It seems implausible that hypothermic Ras activation by EGF involves an 

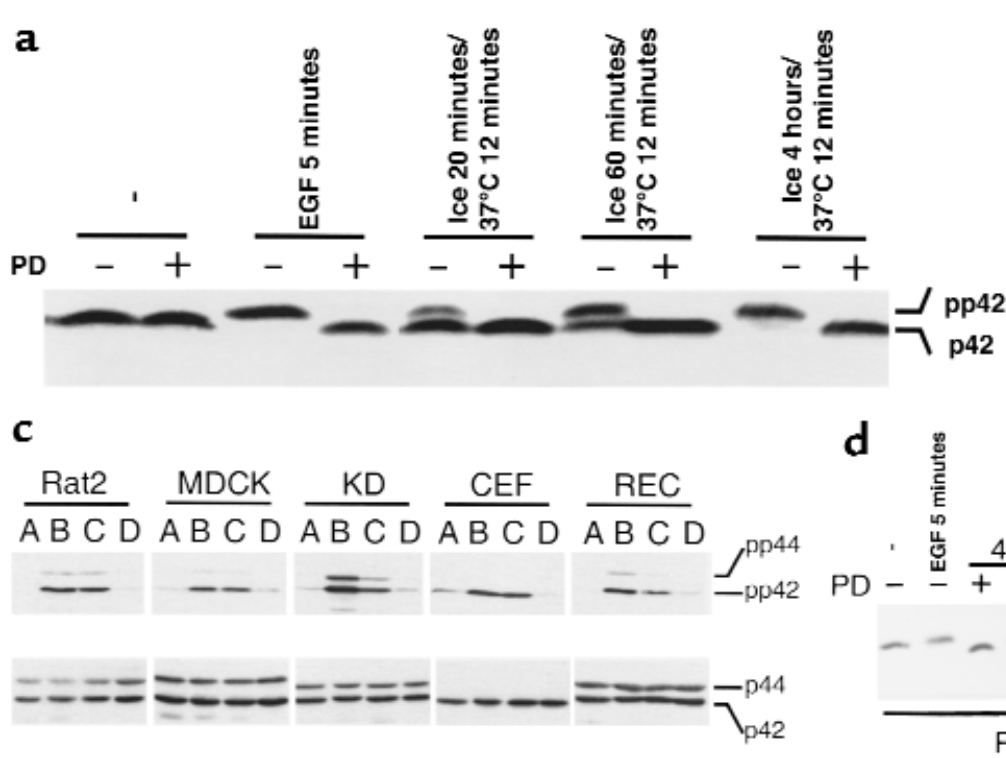

b

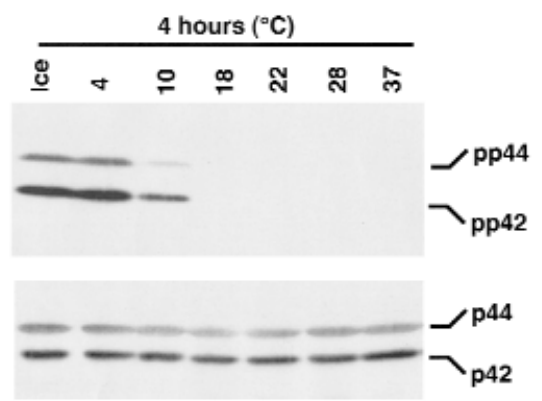

C

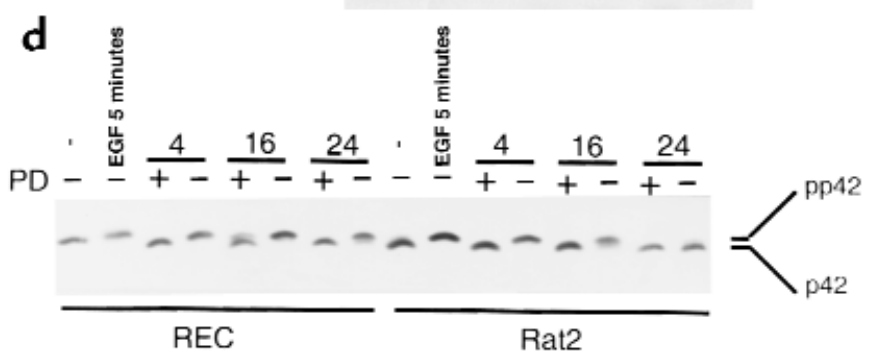

Figure 5

Activation of Erk in response to various hypothermic conditions and in different cell types. (a) Rat2 cells were left untreated, stimulated with EGF at $37^{\circ} \mathrm{C}$, or incubated on ice for various amounts of time followed by warming to $37^{\circ} \mathrm{C}$ for 12 minutes. When indicated, cells were given a pretreatment of the Mek inhibitor PD098059 (50 $\mu \mathrm{M})$ for 90 minutes at $37^{\circ} \mathrm{C}$. Erk activation was assessed using the mobility shift assay. The positions of inactive p42 and active pp42 Erk are indicated on the right. (b) Rat2 cells were exposed to various temperatures for 4 hours and then warmed to $37^{\circ} \mathrm{C}$ for 5 minutes. Top: Erk activation was determined with an immunoblot method that uses a primary antibody that recognizes the dually phosphorylated active forms of Erk. Bottom: Equivalence of protein loading was demonstrated by immunoblotting a parallel blot with an antibody that recognizes total Erk. The positions of doubly phosphorylated pp42 and pp44 Erk and total p42 and p44 Erk are shown on the right. (c) Rat2 cells, MDCK cells (canine kidney epithelial cells), KD cells (human primary fibroblasts), CEF (primary chicken embryo fibroblasts), and REC (primary rat embryo fibroblasts) were treated as described below, and Erk activation was assessed using the immunoblotting assay described in $\mathbf{b}$. A, untreated; B, acute growth factor treatment for 5 minutes at $37^{\circ} \mathrm{C}$; C, incubation on ice for 4 hours followed by warming to $37^{\circ} \mathrm{C}$ for 5 minutes; D, incubation on ice for 30 minutes followed by acute growth factor treatment on ice for 5 minutes. Acute growth factor stimulation was EGF ( $100 \mathrm{ng} / \mathrm{mL})$ for all cell types except CEFs, which were stimulated with $10 \%$ FBS. (d) RECs and rat 2 cells were left untreated, stimulated with EGF, or incubated on ice for 4,16 , or 24 hours and then warmed to $37^{\circ} \mathrm{C}$ for 10 minutes. When indicated, cells were given a pretreatment of the Mek inhibitor PD098059 (50 $\left.\mu \mathrm{M}\right)$ for 90 minutes at $37^{\circ} \mathrm{C}$. Erk activation was assessed using a mobility shift assay. Note that only in a and $\mathbf{d}$ were SDS-PAGE conditions designed to resolve phosphorylated and nonphosphorylated forms of Erk.

inhibition of GAPs coupled with spontaneous exchange, as the reaction occurs so quickly. These results bolster our argument that Ras-GEFs can function at $0^{\circ} \mathrm{C}$ in vivo and are part of the mechanism whereby hypothermic stress leads to slow Ras activation in the absence of acute EGF stimulation (see earlier discussion).

Raf activation involves recruitment to the plasma membrane, interaction with Ras-GTP, and a complex series of events involving protein kinases and probably lipid regulators $(33,34)$. We do not know which EGF-induced events are inhibited by cold, although our preliminary experiments suggest that Raf fails to associate with the membrane at $0^{\circ} \mathrm{C}$ (Chan, E.Y.W., and Stone, J.C., unpublished observations). Ras-GTP and the isolated Ras-binding domain of Raf interact with high affinity at low temperature in vitro (35), but the protein complex containing full-length Raf in vivo (36) might behave differently.

Erk activation has been observed after recovery from both brief and prolonged hypothermia, and it occurs at temperatures frequently experienced by many vertebrate cells. The response has been observed in both primary cell populations and established cell lines. The 2 temperatureregulation mechanisms influencing Ras-Erk signaling, activation of Ras during hypothermia and the inhibition of EGF signaling, appear to be widespread in cultured ver- tebrate cells. Our observations on temperature regulation of Ras signaling could have important implications for understanding the behavior of normal vertebrate cells exposed to hypothermic stress. We hypothesized that RasErk signaling during recovery from hypothermia is part of a protective mechanism, and we predicted that pharmacologic inhibition of this pathway in cultured cells would exacerbate hypothermic damage and reduce cell viability. To our surprise, Mek inhibitors increased cell viability. This effect is completely reproducible, and it has been seen with 4 cell types. It occurs over a range of stress periods, and the magnitude of this effect is up to 40 -fold (viability increased from $0.5 \%$ to $20 \%$; Figure $6 \mathrm{c}$ ).

In some cellular contexts, Ras-Erk signaling has been proposed to contribute to apoptosis $(11,12,37)$, and hypothermic stress is a known trigger of apoptosis in a number of systems (19-21). Indeed, when rat 2 cells were warmed after prolonged hypothermia, we observed DNA fragmentation characteristic of apoptosis, and the amount of fragmented DNA was significantly reduced when the Mek inhibitor was present (Chan, E.Y.W., and Stone, J.C., unpublished observations). However, the idea that hypothermic activation of Ras-Erk signaling reflects some program that normally functions to rid vertebrates of damaged cells remains speculative. 

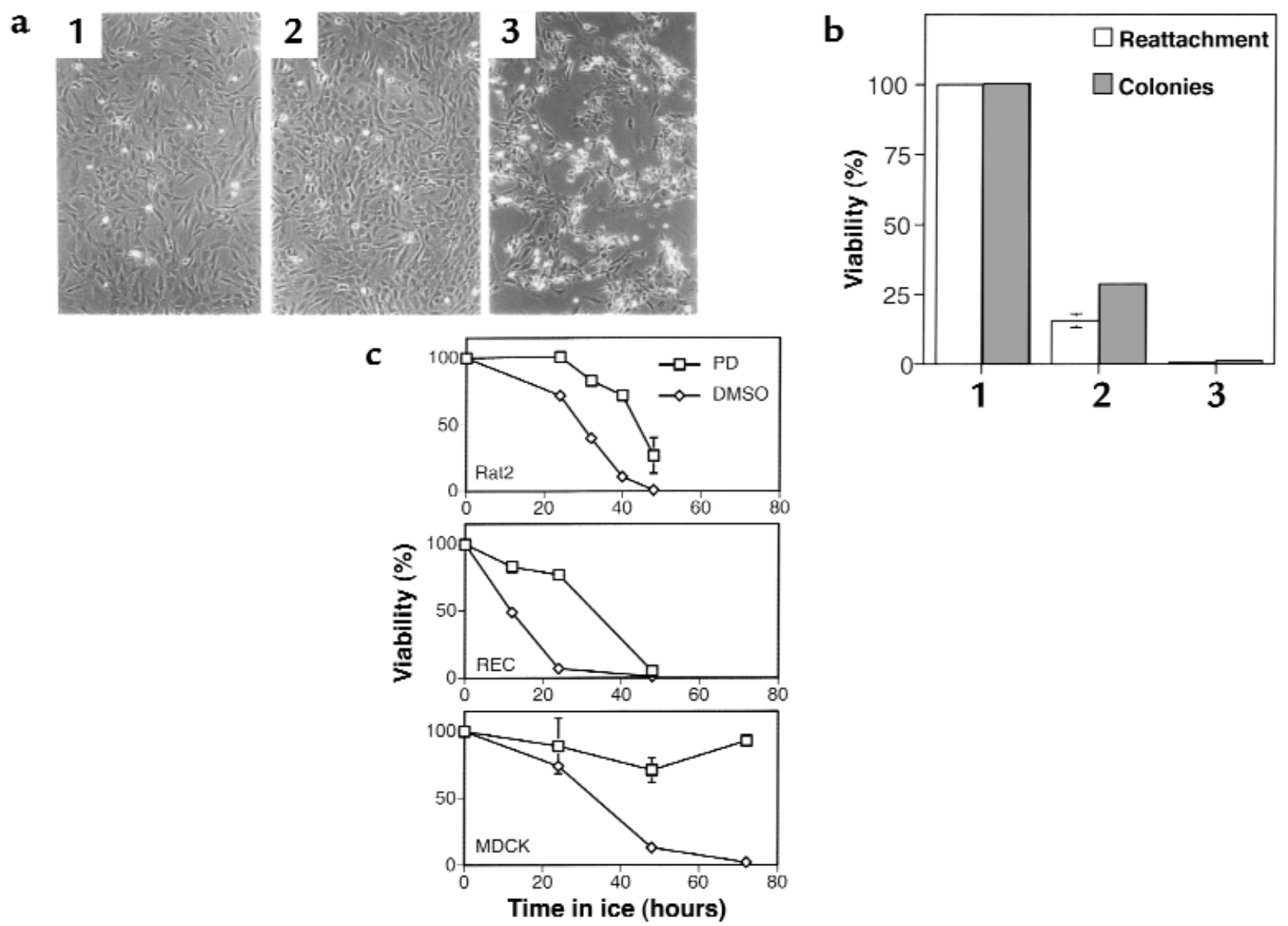

Figure 6

The biologic response of cells to prolonged hypothermic stress and the effects of inhibiting Erk activation using PD098059. (a)RECs were untreated (1) or given a prolonged incubation on ice followed by warming to $37^{\circ} \mathrm{C}$ for 4 hours in the presence (2) or absence (3) of 50 $\mu \mathrm{M}$ PD098059. The duration of the ice incubation was either 16 hours (a) or 24 hours (b). (a) Cell morphology 4 hours after rewarming. (b) Cell viability as determined by a reattachment assay and by the formation of colonies. (c) Cells of the indicated type were incubated on ice for various times, either in the presence or absence of $50 \mu \mathrm{M}$ PD098059, and warmed to $37^{\circ} \mathrm{C}$ for 4 hours. Cell viability was assessed using the reattachment assay. For rat 2 and MDCK cells, each value is the average from 3 independent samples with the standard deviation indicated.

Even if hypothermic Ras-Erk signaling does normally function to promote cell death, other factors must be important in determining the overall response to prolonged hypothermia, as shorter periods of hypothermic stress lead to strong Erk signaling without the detrimental effect on cell viability. Perhaps some biochemical responses that promote cell viability come into play after shorter periods of hypothermic stress, whereas the RasErk pathway dominates the response after prolonged hypothermia. In this context, it should be noted that RasGTP can stimulate PI3 kinase, which can lead to antiapoptotic signaling through Akt/protein kinase $\mathrm{B}(11,12)$. Furthermore, hypothermic stress can lead to activation of NF- $\mathrm{KB}(38)$, and NF- $\mathrm{KB}$ can reduce Ras-induced apoptosis in rodent fibroblasts (37). Thus, modest hypothermia might stimulate at least 2 anti-apoptosis pathways.

In any case, our results suggest a practical avenue that might be exploited to improve the survival of clinically useful cells in cold storage.

\section{Acknowledgments}

The authors thank $\mathrm{L}$. Wang for useful discussions on temperature regulation; Nancy Dower, Mike Schultz, and Ellen Shibuya for careful reading of this manuscript; Giddeon Bollag for P120GAP; and Katherine Day for the KD cells. This work was supported by grants from the National Cancer Institute of Canada.

1. Lowy, D.R., and Willumsen, B.M. 1993. Function and regulation of Ras. Annu. Rev. Biochem. 62:851-891.

2. Chen, W.S., et al. 1987. Requirement for intrinsic protein tyrosine kinase in the immediate and late actions of the EGF receptor. Nature. 328:820-823.

3. Buday, L., and Downward, J. 1993. Epidermal growth factor regulates p21ras through the formation of a complex of receptor, grb2 adapter protein, and Sos nucleotide exchange factor. Cell. 73:611-620.

4. Migliaccio, E., et al. 1997. Opposite effects of the p52shc/p46shc and p66shc splicing isoforms on the EGF receptor-MAP kinase-fos signalling pathway. EMBO J. 16:706-716.

5. Marshall, C.J. 1995. Specificity of receptor tyrosine kinase signaling: transient versus sustained extracellular signal-regulated kinase activation. Cell. 80:179-185.

6. Boguski, M.S., and McCormick, F. 1993. Proteins regulating Ras and its relatives. Nature. 366:643-654.

7. Peeper, D.S., et al. 1997. Ras signalling linked to the cell-cycle machinery by the retinoblastoma protein. Nature. 386:177-181.

8. Hughes, P.E., et al. 1997. Suppression of integrin activation: a novel function of a Ras/Raf-initiated MAP kinase pathway. Cell. 88:521-530.

9. Schlaepfer, D.D., Hanks, S.K., Hunter, T., and van der Geer, P. 1994. Integrin-mediated signal transduction linked to Ras pathway by GRB2 binding to focal adhesion kinase. Nature. 372:786-791.

10. Rodriguez-Viciana, P., et al. 1997. Role of phosphoinositide 3-OH kinase in cell transformation and control of the actin cytoskeleton by Ras. Cell. 89:457-467. 
11. Kauffmann-Zeh, A., et al. 1997. Suppression of c-Myc-induced apoptosis by Ras signalling through PI(3)K and PKB. Nature. 385:544-548.

12. Khwaja, A., Rodriguez-Viciana, P., Wennström, S., Warne, P.H., and Downward, J. 1997. Matrix adhesion and Ras transformation both activate a phosphoinositide 3-OH kinase and protein kinase B/Akt cellular survival pathway. EMBO J. 16:2783-2793.

13. Okuda, K., et al. 1992. Granulocyte-macrophage colony-stimulating factor, interleukin-3, and steel factor induce rapid tyrosine phosphorylation of p42 and p44 MAP kinase. Blood. 79:2880-2887.

14. Campos-González, R., and Glenney, J.R., Jr. 1991. Temperature-dependent tyrosine phosphorylation of microtubule-associated protein kinase in epidermal growth factor-stimulated human fibroblasts. Cell Regul. 2:663-673.

15. Belzer, F.O., and Southard, J.H. 1988. Principles of solid-organ preservation by cold storage. Transplantation. 45:673-676.

16. Hochachka, P.W. 1986. Defense strategies against hypoxia and hypothermia. Science. 231:234-241.

17. Mcanulty, J.F., Ametani, M.S., Southard, J.H., and Belzer, F.O. 1996. Effect of hypothermia on intracellular $\mathrm{Ca} 2+$ in rabbit renal tubules suspended in UW-gluconate preservation solution. Cryobiology. 33:196-204.

18. Liu, B., Wang, L.C.H., and Belke, D.D. 1991. Effect of low temperature on the cytosolic free $\mathrm{Ca} 2+$ in rat ventricular myocytes. Cell Calcium. 12:11-18

19. Gregory, C.D., and Milner, A.E. 1994. Regulation of cell survival in Burkitt lymphoma: implications from studies of apoptosis following cold-shock treatment. Int. J. Cancer. 57:419-426.

20. Kruman, I.I., Gukovskaya, A.S., Petrunyaka, V.V., Beletsky, I.P., and Trepakova, E.S. 1992. Apoptosis of murine BW 5147 thymoma cells induced by cold shock. J. Cell. Physiol. 153:112-117.

21. Perotti, M., et al. 1990. Calcium-dependent DNA fragmentation in human synovial cells exposed to cold shock. FEBS Lett. 259:331-334.

22. Topp, W.C. 1981. Normal rat cell lines deficient in nuclear thymidine kinase. Virology. 113:408-411.

23. Stone, J.C., Colleton, M., and Bottorff, D. 1993. Effector domain mutations dissociate $\mathrm{p} 21 \mathrm{ras}$ effector function and GTPase-activating protein interaction. Mol. Cell. Biol. 13:7311-7320.

24. Morgenstern, J.P., and Land, H. 1990. Advanced mammalian gene transfer: high titer retroviral vectors with multiple drug selection markers and a complementary helper-free packaging cell line. Nucleic Acids Res. 18:3587-3596
25. Pear, W.S., Nolan, G.P., and Scott, M.L., and Baltimore, D. 1993. Production of high-titer helper-free retroviruses by transient transfection. Proc. Natl. Acad. Sci. USA. 90:8392-8396.

26. Taylor, S.J. and Shalloway, D. 1996. Cell cycle-dependent activation of Ras. Curr. Biol. 6:1621-1627.

27. Leonardsen, L., DeClue, J.E., Lybæk, H., Lowy, D.R., and Willumsen, B.M. 1996. Rasp21 sequences opposite the nucleotide binding pocket are required for GRF-mediated nucleotide release. Oncogene. 13:2177-2187.

28. Bottorff, D., Stang, S., Agellon, S., and Stone, J.C. 1995. RAS signalling is abnormal in a c-raf1 MEK1 double mutant. Mol. Cell. Biol. 15:5113-5122.

29. Poe, M., Scolnick, E.M., and Stein, R.B. 1985. Viral Harvey ras p21 expressed in Escherichia coli purifies as a binary one-to-one complex with GDP. J. Biol. Chem. 260:3906-3909.

30. Ebinu, J.O., et al. 1998. RasGRP, a Ras guanyl nucleotide-releasing protein with calcium- and diacylglycerol-binding motifs. Science. 280:1082-1086

31. Alessi, D.R., Cuenda, A., Cohen, P., Dudley, D.T. and Saltiel, A.R. 1995. PD098059 is a specific inhibitor of the activation of the mitogen-activated protein kinase kinase in vitro and in vivo. J. Biol. Chem. 270:27489-27494.

32. Favata, M.F., et al. 1998. Identification of a novel inhibitor of mitogenactivated protein kinase kinase. J. Biol. Chem. 273:18623-18632.

33. Barnard, D., Diaz, B., Clawson, D., and Marshall, M. 1998. Oncogenes, growth factors and phorbol esters regulate Raf-1 through common mechanisms. Oncogene. 17:1539-1547.

34. Ghosh, S., et al. 1994. The cysteine-rich region of raf- 1 kinase contains zinc, translocates to liposomes, and is adjacent to a segment that binds GTP-ras. J. Biol. Chem. 269:10000-10007.

35. Warne, P.H., Rodriguez-Viciana, P., and Downward, J. 1993. Direct interaction of Ras and the amino-terminal region of Raf- 1 in vitro. Nature. 364:352-355.

36. Wartmann, M., and Davis. R.J. 1994. The native structure of the activated Raf protein kinase is a membrane-bound multi-subunit complex. J. Biol. Chem. 269:6695-6701.

37. Mayo, M.W., et al. 1997. Requirement of NF-кB. activation to suppress p53-independent apoptosis induced by oncogenic Ras. Science. 278:1812-1815.

38. Rosette, C. and Karin, M. 1995. Cytoskeletal control of gene expression: Depolymerization of microtubules activates NF- $\mathrm{kB}$. J. Cell Biol. 128:1111-1119. 